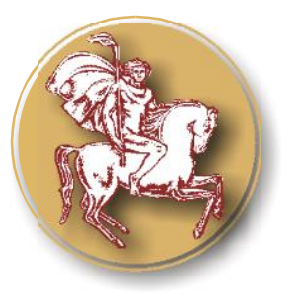

Trakia Journal of Sciences, No 1, pp 8-12, 2019

Copyright (C) 2019 Trakia University Available online at:

Original Contribution

\title{
TERRAFORMING MARS IS NOT OUT OF THE QUESTION YET - AND MICROSCOPIC ALGAE COULD HELP
}

\author{
Iv. Vasileva, A. Ivanova, S. Alexandrov* \\ Institute of Plant Physiology and Genetics, Bulgarian Academy of Sciences, Sofia, Bulgaria
}

\begin{abstract}
Recently some researchers have gathered around the claim that the likelihood for terraformation of Mars is slim, either because human technology is not up to the task, or the planet does not posses all the necessary resources to allow the process to be completed successfully. This manuscript takes a closer look both at the latest and previous scientific articles, optimistic and skeptical, while trying to reassess the terraforming potential of the planet. To achieve that, we summarized results from different experiments conducted with algae and higher plants. According to our reevaluation, it is concluded that even if the skeptical papers are right, and the others are overly optimistic, partial terraformation of Mars is still possible. It is also suggested that terraforming the planet partially could be a good option if we want to protect the local organisms, assuming that they exist.
\end{abstract}

Key words: spaceflight, terraformation, planets, phycology, chroococcidiopsis, colonization, future

\section{INTRODUCTION}

Terraformation of planets, which means changing their environment in order to make them suitable for Earth lifeforms, is not a new concept both to the science fiction and science. The word "terraforming" appeared first in the novels of Jack Williamson in 1940s, and the first non-fiction book dedicated entirely to the subject was published by James Oberg in 1981 (1). With the interest of exploring Mars being on the rise during the last two decades, the prospects of its terraformation have been discussed by many researchers such as Christopher McKay (1, 2), Robert Zubrin (2) and Martyn J Fogg (3). The arguments in favor of terraformation are clear: there are no known planets or satellites in the Solar System which allow humans to live there without the protection of spacecraft or spacesuits. Mars is no different, but it has several advantages. One of the most important of them is the fact that the Martian day has a mean period of 24 hours and 39 minutes (4). Here the obvious

\footnotetext{
*Correspondence to: Svetoslav Alexandrov, Institute of Plant Physiology and Genetics, Bulgarian Academy of Sciences, "Acad. Georgi Bontchev” str. Bl. 21, 1113-Sofia, Bulgaria, e-mail: saturn@gbg.bg
}

implication is that it would be easier for Earth life to adapt to Mars due to the similar length of the earth day, compared to the adaptation on other satellites and planets with extremely long or short days. Another advantage is that we already know that Mars used to be wetter and warmer in the past, and there is still a lot of water present on the planet in the form of ice or frozen mud (5). Also, current robotic missions have discovered that the mineralogy and chemistry of the Mars soil makes it suitable for life. For example, Mars rover Curiosity has found fixed nitrogen in the form of nitrates, in contrast to atmospheric nitrogen which is inaccessible to most organisms (6). The presence of important salts has also been detected, including carbonates and sulfates (7).

Discussions of the potential terraformation of Mars are usually focused on two questions: "Should we?" and "Can we?". The first question deals with the ethical aspects of terraformation and whether it is morally permissive to do it (8). Since this has already been discussed elsewhere, it will not be the main focus of this paper.

The second one deals with the likelihood of the concept. It could be divided to another two 
different subtopics. The first subtopic is about the technology: what kind of machines and tools (existing or futuristic) are needed in order to change the environment of Mars. Arguments pro are that the technology of the $21^{\text {st }}$ century is adequate enough, for example, mirrors with dimension of $100 \mathrm{~km}$ radius could be used in order to vaporize the carbon dioxide in the Martian polar caps (2). But other researchers have argued recently that existing technologies are not up to the task, because certain hazards such as altered gravity and space radiation cannot be mitigated, and terraforming could be unpredictable and not fully controllable (9). Regardless of the argumentation "for" or "against", we can agree that human technology is a subject to continuous development and assume that certain problems which seem unsolvable today and beyond our control, may find their solution in the near future. Eventual technological breakthroughs won't be discussed here and in this paper we will limit ourselves to our existing scientific knowledge and technological development.

The other subtopic deals with the planet Mars itself. The question is whether the planet has all the available resources in order to induce successful terraformation. A skeptical paper was published in 2018 describing results from a major NASA-sponsored investigation. The authors of this study conclude that although Mars possesses carbon dioxide and water in reservoirs like the polar caps, mineral and soils, even if we find a way to process all the resources, this would thicken the atmospheric pressure to only $7 \%$ that of Earth. Another concern is that not all of the reservoirs can be accessed easily. In the past it has been suggested that the easiest approach terraformers could use is just to heat the polar caps in order to release their $\mathrm{CO}_{2}$ and $\mathrm{H}_{2} \mathrm{O}$. However, this procedure would only increase the pressure to less than 15 mbar, just twice the current atmospheric pressure (10). The conclusions of the authors are clear: there is no way we can transform Mars to a point humans can survive on its surface without protective suit - it is the planet that lacks the necessary resources.

\section{DISCUSSION}

Is Mars terraformation possible? If we take a serious look at the current scientific literature, the answer is ambiguous. The NASAsponsored study (Jakosky and Edwards) from 2018 states that "terraforming Mars is not possible using present-day technology" (10).
Researchers like MkCay et al (11) have stated that it "may be possible to transform it (i.e. Mars) into a planet suitable for habitation by plants, and conceivably humans". Then we have Fogg (12), who has stated that terraformation "does not appear technologically impossible", but "whether it will actually happen is an unanswerable question". The variations of the answer may have an easy explanation - the term "terraformation" carries quite broad sense and different researchers may imply variable meaning by using it. It has already been noted in the scientific literature that while the best definition of the term "terraformation" is "changing the conditions of a planet or a moon in order to make it suitable for life", it does not need to be used in a strict sense: "making them suitable for human life", with the emphasis on humans. It may mean changing the conditions just enough for plant life to thrive and produce food for the future colonizers, even if they still won't be able to live on the surface without protective clothing, or it may mean making just a fraction of the other world inhabitable, if not the whole one (13). Taking this note into account, the latest skeptical articles $(9,10)$ are not the death knell for the idea of terraforming Mars - not just yet. Mars may never become entirely inhabitable for future astronauts, but humanity could still turn it into a proper second home for humans - even if only parts of it are processed.

Moreover, even if we cannot provide all necessary conditions for human life, other organisms have fewer requirements. Certain cyanobacteria, namely Chroococcidiopsis sp., can grow in extreme hot and cold deserts and it has been considered for a long time as a potential candidate for Martian terraformation (13). Furthermore, in a recent study from 2018 it was reported that the cyanobacteria has been successfully and continuously cultivated for a long period of time. Researchers have estimated the following facts: Chroococcidiopsis can grow for 60 days, accumulate biomass of $16.08 \mathrm{~g} / \mathrm{m}^{2} / \mathrm{d}$. The biomass is rich in phycobiliproteins and essential fatty acids, as such it is suitable for animal food, not toxic to fish, and most importantly - the produced biomass has the quality to settle spontaneously, which eliminates the need of expensive centrifugation or separation techniques (14). We can consider the result optimistic, especially concerning the lack of toxicity to fish. Still, more investigations are necessary in this area as it 
has been reported in the past that some strains of Chroococcidiopsis are producers of $\beta-\mathrm{N}$ methylamino-L-alanine, which is a neurotoxic amino acid (15). If the positive results are confirmed in future studies, Chroococcidiopsis could be a great asset in terraformation of Mars. A research performed in the last two years confirms the adaptive properties of the cyanobacteria to desiccation and radiation to the point of being able to survive under simulated Martian conditions (16). Pessimistic prospects concerning terraformation in the strict sense (10) should not bother us. We need to change Mars conditions (entirely or partially) just enough to allow exponential growth of Chroococcidiopsis to generate oxygen, feed animals, or perhaps even humans.

Modern research on the feasibility on terraformation focuses on whether processing Mars resources would generate enough atmospheric pressure for Earth lifeforms to exist. Past studies were focused more on whether plants can survive in simulated Martian environment and low atmospheric pressure. Here it is good to be reminded that it has been estimated that wheat (Triticum aestivum ) is able to germinate and grow under low pressure conditions, even though the germination rate is lower compared to Earth atmosphere control experiment (17). This means that the pressure itself is not the most important factor in order to terraform Mars to the point to grow plants. In order to enhance the germination rate, microalgae could help. Experiments conducted with microscopic organisms like the desert-thriving Arthronema africanum can positively influence the germination of the plant Tribulus terrestris, which is also able to grow in deserts (18). Similar research has been reported this year that the green microalga Coelastrella sp. positively influences the seed germination and the growth of pepper (Capsicum annulum ) (19). We recommend further experiments with seed germination in the presence of algae under simulated Mars conditions. This way it could be proven if the idea works and is applicable in terraformation.

There is one last thing that needs to be discussed with regards to Mars colonization and eventual terraformation - the factor of unpredictability, a concern which is correctly being noted in skeptical papers (9). Here we have to agree that while there is certain advance in the field of creating regenerative life support systems (13), creating an artificial
VASILEVA IV. et al. biosphere, the ultimate goal of terraformation, is an entirely different thing. The only known example of a functioning and self-sustainable biosphere, of course, is our own planet. Replicating this is extremely difficult and the efforts have met with mixed success. In Europe there is a project called MELiSSA with a primary goal to establish the minimal possible self-sustaining biosphere (20). In Japan there was a facility called Biosphere $\mathbf{J}$ (21), while in Russia efforts have been concentrated on the Bios-1, Bios-2 and Bios-3 projects (22). So far the largest effort has been attempted in Arizona, USA, in a facility known as Biosphere 2. Its construction took place between 1984 and 1991 and the area is about $13000 \mathrm{~m}^{2}$. The overall result of this attempt to create an artificial biosphere is largely regarded as a failure in the public space - the system was not able to support an entirely closed system, independent of the Earth biosphere and supplying humans with food, water and air (23). During the first mission (between 1991 and 1993) and the second mission (in 1994) crews dealt with many unexpected problems. For example, out of six cockroach species introduced in Biosphere 2, one of them (the Australian cockroach, or Periplaneta australasiae) proliferated unexpectedly (24). A certain type of ants (Paratrechina longicornis) feasted on the cockroaches, until it became invasive itself and this continued until the populations of both the cockroaches and ants significantly decreased $(24,25)$. Yet we cannot easily dismiss of the whole project as a total fiasco the fact that we learned such important lessons means what we are prepared to deal with them, if they occur again. Thanks to Biosphere 2 we now understand complex bionic system much better (26).

The experiments in the Russian Bios facilities have been less promulgated even though they offer a lot of positive evidence on the terraformation prospects. Much of the conducted research has been done with microalgae. More than half a century ago, in 1965 in the Bios-1 facility, it was proven that the green alga Chlorella vulgaris is able to regenerate the atmosphere for one human in a sealed $12 \mathrm{~m}^{3}$ chamber, by connecting it with an $18 \mathrm{~L}$ photobioreactor. The algal system, by removing carbon dioxide and producing oxygen, accounted for $20 \%$ of the water, air and food quantities required by one human, which means that a result of $20 \%$ closure was achieved (27). Research activities in 
subsequent years led to reporting that the index of closure in terms of mass of water and air could reach as high as $90 \%$ (28). These results imply that the past advancement of human sciences and technologies has made great leaps in order to understand how to turn $\mathrm{CO}_{2}$ into $\mathrm{O}_{2}$, which is an essential component of terraforming parts of the Red Planet. Such partial terraforming could even make the planet suitable for human life.

\section{CONCLUSIONS}

The assessment of the likelihood of terraformation is a hard task, which requires analyzing scientific results not only from the recent years, but also taking into account the decade-long research activities, conducted by many different institutions and organizations. Although there is plenty of ground for skepticism, there are also papers that have provided results which could be interpreted as being in favor of Martian terraformation, especially if we consider the term in its broader meaning. Thus said, this idea is not out of the question yet. If the skeptical papers are right, and the planet does not possess the resources to be fully inhabitable, the possibility to terraform Mars partially still exists. In the light of opposition to human colonization based on modern biocentrism, which means that if Mars has its own life we should not disturb it, partial terraformation could be a good compromise if no consensus is reached between human spaceflight deniers and supporters. We may still leave local life pockets undisturbed and left alone as wildlife sanctuaries, while the uninhabited parts on Mars could be sealed from the rest of the planet and thoroughly changed via the biological actions of photosynthetic microorganisms.

\section{REFERENCES}

1. McKay, C. P., On Terraforming Mars. Extrapolation, 23(4): 309-314, 1982.

2. Zubrin, R. M. and McKay, C. P., Technological requirements for terraforming Mars. $J \mathrm{Br}$ Interplanet Soc, 50: 309, 1997.

3. Fogg, M. J., Terraforming: a review for environmentalists. Environmentalist, 13(1): 7-17, 1993.

4. Appelbaum, J. and Flood, D. J., Solar radiation on Mars. Sol Energy, 45(6): 353363, 1990.

5. Zubrin, R., The case for Mars. Simon and Schuster, NY, USA, 2012.

6. Stern, J. C., Sutter, B., Freissinet, C., Navarro-González, R., McKay, C. P.,
VASILEVA IV. et al.

Archer, P. D. .... and Fairen, A. G., Evidence for indigenous nitrogen in sedimentary and aeolian deposits from the Curiosity rover investigations at Gale crater, Mars. Proc Natl Acad Sci USA, 201420932, 2015.

7. Hecht, M. H., Kounaves, S. P., Quinn, R. C., West, S. J., Young, S. M. M., Ming, D. W. ... and DeFlores, L. P., Detection of perchlorate and the soluble chemistry of martian soil at the Phoenix lander site. Science, 325(5936): 64-67, 2009.

8. Alexandrov, S., Planetary Protection for Mars: Time for Reconsideration. Bangladesh Journal of Bioethics, 7(2): 3134, 2016.

9. Szocik, K., Should and could humans go to Mars? Yes, but not now and not in the near future. Futures (In Press), 2018.

10.Jakosky, B. M. and Edwards, C. S., Inventory of $\mathrm{CO} 2$ available for terraforming Mars. Nat Astron, 2(8): 634, 2018.

11.McKay, C. P., Toon, O. B. and Kasting, J. F., Making Mars habitable. Nature, 352(6335): 489-496, 1991.

12.Fogg, M. J., Terraforming Mars: A Review of Concepts. In: Engineering Earth, Springer, Dordrecht, pp. 2217-2225, 2011.

13. Alexandrov, S. D., Algal research in space: History, current status and future prospects. Innovare Journal of Life Sciences, 1: 1-4, 2016.

14.Das, P., Quadir, M. A., Chaudhary, A. K., Thaher, M. I., Khan, S., Alghazal, G. and Al-Jabri, H., Outdoor Continuous Cultivation of Self-Settling Marine Cyanobacterium Chroococcidiopsis sp. Ind Biotechnol, 14(1): 45-53, 2018.

15.Cox, P. A., Banack, S. A., Murch, S. J., Rasmussen, U., Tien, G., Bidigare, R. R. ... and Bergman, B., Diverse taxa of cyanobacteria produce $\beta$-N-methylaminoL-alanine, a neurotoxic amino acid. Proc Natl Acad Sci USA, 102(14): 5074-5078, 2005.

16.Billi, D., Verseux, C., Mosca, C., Baqué, M. and Wilmotte, A., Unravelling the secret of the resistance of desert strains of Chroococcidiopsis to desiccation and radiation. In: Book of abstracts, XIIth SCAR Biology Symposium, Leuven, Belgium, p. 152, 2017.

17.Schwartzkopf, S. H. and Mancinelli, R. L., Germination and growth of wheat in simulated Martian atmospheres. Acta astronaut, 25(4): 245-247, 1991. 
18.Petkov, G., Could Microalgae Enhance the Germination of Tribulus Terrestris L. seeds?. Biotechnol Biotechnol Equip, 24(sup1): 53-55, 2010.

19.Georgieva, A., Toshkova-Yotova, T., Pilarski, P., Petrova, D., Zhiponova, M. and Chaneva, G., Influence of Green Microalga Coelastrella sp. on seed germination and growth of Capsicum annulum L. In: Scientific Conference "Klimentovi Dni", Book of Abstracts, Sofia, 2018.

20.Walker, J. and Granjou, C., MELiSSA the minimal biosphere: Human life, waste and refuge in deep space. Futures, 92: 59-69, 2017.

21.Nakano, S., Uchida, T., Ishigamori, I., Sugawara, S. and Nitta, K., Dynamic Simulation of Pressure Control System for the Closed Ecology Experiment Facility. Trans Jpn Soc Mech Eng, 64 (617): 107114, 1998.

22.Salisbury, F. B., Gitelson, J. I. and Lisovsky, G. M., Bios-3: Siberian experiments in bioregenerative life support. BioScience, 47(9): 575-585, 1997.
VASILEVA IV. et al.

23. Cohen, J. E. and Tilman, D., Biosphere 2 and Biodiversity--The Lessons So Far. Science, 274(5290): 1150-1151, 1996.

24.Walford, R. L., Biosphere 2 as voyage of discovery: The serendipity from inside. AIBS Bulletin, 52(3): 259-263, 2002.

25.Wetterer, J. K., Miller, S. E., Wheeler, D. E., Olson, C. A., Polhemus, D. A., Pitts, M. ... and Harken, E. L., Ecological dominance by Paratrechina longicornis (Hymenoptera: Formicidae), an invasive tramp ant, in biosphere 2. Fla Entomol, 381-388, 1999.

26. Allen, J. P., Nelson, M. and Alling, A., The legacy of Biosphere 2 for the study of biospherics and closed ecological systems. Adv Space Res, 31(7): 1629-1639, 2003.

27. Salisbury, F. B., Gitelson, J. I. and Lisovsky, G. M., Bios-3: Siberian experiments in bioregenerative life support. BioScience, 47(9): 575-585, 1997.

28.Somova, L. A. and Pechurkin, N. S., Management and control of microbial populations' development in LSS of missions of different durations. Adv Space Res, 35(9): 1621-1625, 2005. 